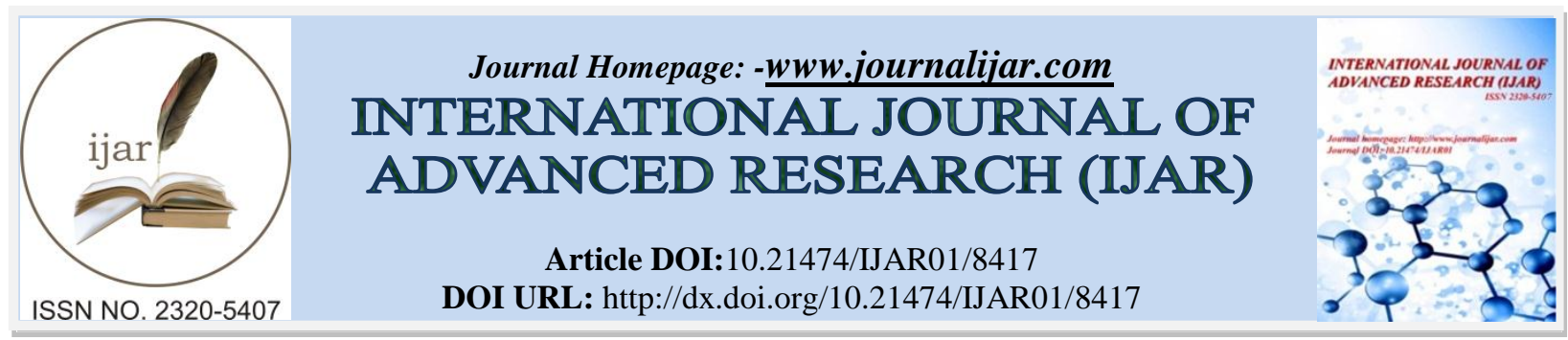

RESEARCH ARTICLE

\title{
LINEAR PRIME LABELING OF SOME DIRECT CYCLE RELATED GRAPHS.
}

\section{Sunoj B $\mathbf{S}^{1}$ and Mathew Varkey $\mathbf{T} \mathbf{K}^{2}$.}

1. Department of mathematics, government polytechnic college, attingal.

2. Department of mathematics, $\mathrm{t} \mathrm{k} \mathrm{m}$ college of engineering, kollam.

\section{Manuscript Info}

\section{Manuscript History}

Received: 14 November 2018

Final Accepted: 16 December 2018

Published: January 2019

Key words:-

Graph labeling, linear, prime labeling,

prime graphs, direct graphs, cycle.

\section{Abstract}

Linear prime labeling of a graph is the labeling of the vertices with $\{0,1,2---, p-1\}$ and the direct edges with twice the value of the terminal vertex plus value of the initial vertex. The greatest common incidence number of a vertex (gcin) of in degree greater than one is defined as the greatest common divisor of the labels of the incident edges. If the gcin of each vertex of in degree greater than one is one, then the graph admits linear prime labeling. Here we investigated some direct cycle related graphs for linear prime labeling.

Copy Right, IJAR, 2018,. All rights reserved.

\section{Introduction:-}

All graphs in this paper are finite and direct. The direction of the edge is from $v_{i}$ to $v_{j}$ iff $f\left(v_{i}\right)<f\left(v_{j}\right)$. The symbols $\mathrm{V}(\mathrm{G})$ and $\mathrm{E}(\mathrm{G})$ denote the vertex set and edge set of a graph $\mathrm{G}$. The graph whose cardinality of the vertex set is called the order of $\mathrm{G}$, denoted by $\mathrm{p}$ and the cardinality of the edge set is called the size of the graph $\mathrm{G}$, denoted by $\mathrm{q}$. A graph with $p$ vertices and $q$ edges is called a (p,q)- graph.

A graph labeling is an assignment of integers to the vertices or edges. Some basic notations and definitions are taken from [1],[2],[3] and [4] . Some basic concepts are taken from Frank Harary [2]. In this paper we investigated linear prime labeling of some direct cycle related graphs.

\section{Definition:}

Let $\mathrm{G}$ be a graph with $\mathrm{p}$ vertices and $\mathrm{q}$ edges. The greatest common incidence number (gcin) of a vertex of in degree greater than or equal to 2, is the greatest common divisor ( $\mathrm{gcd}$ ) of the labels of the incident edges.

\section{Definition}

A Graph is said to be a di graph if each edge of $\mathrm{G}$ has a direction.

\section{Definition}

In-degree of a vertex in a digraph is the number of edges incident at that vertex.

\section{Main Results:-}

\section{Definition}

Let $\mathrm{G}=(\mathrm{V}(\mathrm{G}), \mathrm{E}(\mathrm{G}))$ be a graph with $\mathrm{p}$ vertices and $\mathrm{q}$ edges . Define a bijection

Corresponding Author:-Sunoj B S.

Address:-Department of mathematics, government polytechnic college, attingal. 
$\mathrm{f}: \mathrm{V}(\mathrm{G}) \rightarrow\{0,1,2,---, \mathrm{p}-1\}$ by $\mathrm{f}\left(\mathrm{v}_{\mathrm{i}}\right)=\mathrm{i}-1$, for every i from 1 to $\mathrm{p}$ and define a 1-1 mapping $f_{l p l}^{*}: \mathrm{E}(\mathrm{G}) \rightarrow$ set of natural numbers $\mathrm{N}$ by $f_{l p l}^{*}\left(v_{i} v_{j}\right)=f\left(v_{i}\right)+2 f\left(v_{j}\right)$ for every direct edge $\mathrm{v}_{\mathrm{i}} \mathrm{v}_{\mathrm{j}}$. The induced function $f_{l p l}^{*}$ is said to admit linear prime labeling, if for each vertex of in degree at least 2, the gcin of the labels of the incident edges is 1.

\section{Definition}

A direct graph which admits linear prime labeling is called linear prime graph.

\section{Theorem}

Cycle $C_{n}(n>2)$ admits linear prime labeling.

\section{Proof:}

Let $\mathrm{G}=\mathrm{C}_{\mathrm{n}}$ and let $\mathrm{v}_{1}, \mathrm{v}_{2},---, \mathrm{v}_{\mathrm{n}}$ are the vertices of $\mathrm{G}$.

Here $|\mathrm{V}(\mathrm{G})|=\mathrm{n}$ and $|\mathrm{E}(\mathrm{G})|=\mathrm{n}$.

Define a function $\mathrm{f}: \mathrm{V} \rightarrow\{0,1,2,---, \mathrm{n}-1\}$ by

Clearly $\mathrm{f}$ is a bijection.

$$
\mathrm{f}\left(\mathrm{v}_{\mathrm{i}}\right)=\mathrm{i}-1, \mathrm{i}=1,2,---, \mathrm{n}
$$

For the vertex labeling $\mathrm{f}$, the induced edge labeling $f_{l p l}^{*}$ is defined as follows

$$
\begin{array}{lll}
f_{l p l}^{*}\left(v_{2 i-1} v_{2 i+1}\right) & =6 \mathrm{i}-2, & \mathrm{i}=1,2,---, \frac{n-2}{2}, \text { if } \mathrm{n} \text { is even. } \\
f_{l p l}^{*}\left(v_{2 i} v_{2 i+2}\right) & \mathrm{i}=1,2,---, \frac{n-1}{2}, \text { if } \mathrm{n} \text { is odd. } \\
& =6 \mathrm{i}+1, & \mathrm{i}=1,2,---, \frac{n-2}{2}, \text { if } \mathrm{n} \text { is even. } \\
f_{l p l}^{*}\left(v_{1} v_{2}\right) & \mathrm{i}=1,2,---, \frac{n-3}{2}, \text { if } \mathrm{n} \text { is odd. } \\
f_{l p l}^{*}\left(v_{n-1} v_{n}\right) & =2 . & \\
\text { Clearly } f_{l p l}^{*} \text { is an injection. } & =3 \mathrm{n}-4 . & \\
\text { gcin of }\left(\mathrm{v}_{\mathrm{n}}\right) & & \operatorname{gcd} \text { of }\left\{f_{l p l}^{*}\left(v_{n-2} v_{n}\right), f_{l p l}^{*}\left(v_{n-1} v_{n}\right)\right\} \\
& =\operatorname{gcd} \text { of }\{3 \mathrm{n}-5,3 \mathrm{n}-4\} & \\
& =1 .
\end{array}
$$

So, gcin of each vertex of in degree greater than one is 1 .

Hence $C_{n}$, admits linear prime labeling.

Example (a) $\mathbf{G}=\mathbf{C}_{6}$.

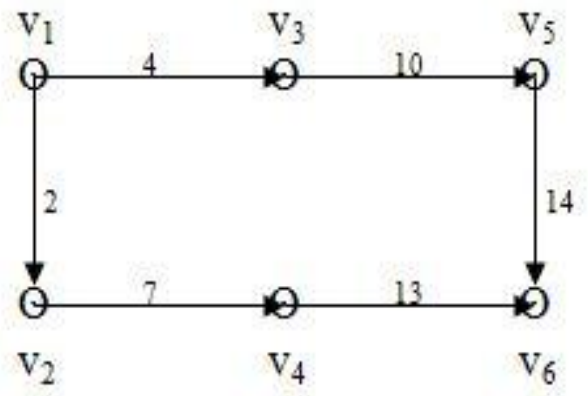

Fig 2.1a:-

Example (b) $\mathbf{G}=\mathbf{C}_{7}$.

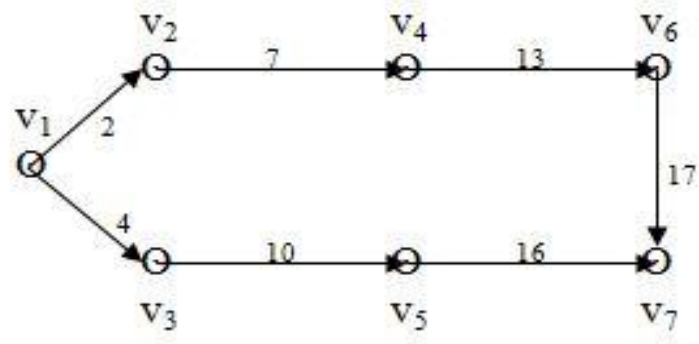

Fig2.1b:- 


\section{Theorem}

Direct graph of two copies of cycle $C_{n}(n>2)$ sharing a common edge admits linear prime labeling.

\section{Proof:}

Let $\mathrm{G}$ be the graph and let $\mathrm{v}_{1}, \mathrm{v}_{2},---, \mathrm{v}_{2 \mathrm{n}-2}$ are the vertices of $\mathrm{G}$.

Here $|\mathrm{V}(\mathrm{G})|=2 \mathrm{n}-2$ and $|\mathrm{E}(\mathrm{G})|=2 \mathrm{n}-1$.

Define a function $\mathrm{f}: \mathrm{V} \rightarrow\{0,1,2,---, 2 \mathrm{n}-3\}$ by

Clearly $\mathrm{f}$ is a bijection.

$$
f\left(v_{i}\right)=i-1, i=1,2,---, 2 n-2
$$

For the vertex labeling $\mathrm{f}$, the induced edge labeling $f_{l p l}^{*}$ is defined as follows

$$
\begin{aligned}
& f_{l p l}^{*}\left(v_{2 i-1} v_{2 i+1}\right) \\
& =6 \mathrm{i}-2 \text {, } \\
& =6 \mathrm{i}+1 \text {, } \\
& f_{l p l}^{*}\left(v_{2 i} v_{2 i+2}\right) \\
& =3 \mathrm{n}-4 \text {. } \\
& f_{l p l}^{*}\left(v_{n-1} v_{n}\right) \\
& =6 \mathrm{n}-10 \text {. } \\
& \mathrm{i}=1,2,---, \mathrm{n}-2 \\
& \mathrm{i}=1,2,---, \mathrm{n}-2 \\
& f_{l p l}^{*}\left(v_{2 n-3} v_{2 n-2}\right) \\
& =\operatorname{gcd} \text { of }\left\{f_{l p l}^{*}\left(v_{n-2} v_{n}\right), f_{l p l}^{*}\left(v_{n-1} v_{n}\right)\right\} \\
& =\operatorname{gcd} \text { of }\{3 n-5,3 n-4\}=1 \text {. } \\
& =\operatorname{gcd} \text { of }\left\{f_{l p l}^{*}\left(v_{2 n-4} v_{2 n-2}\right), f_{l p l}^{*}\left(v_{2 n-3} v_{2 n-2}\right)\right\} \\
& =\operatorname{gcd} \text { of }\{6 n-11,6 n-10\}=1 \text {. }
\end{aligned}
$$

So, $\boldsymbol{g c i n}$ of each vertex of in degree greater than one is 1 .

Hence $\mathrm{G}$, admits linear prime labeling.

Example (a) $G$ be the direct graph of two copies of cycle $C_{6}$ sharing a common edge.

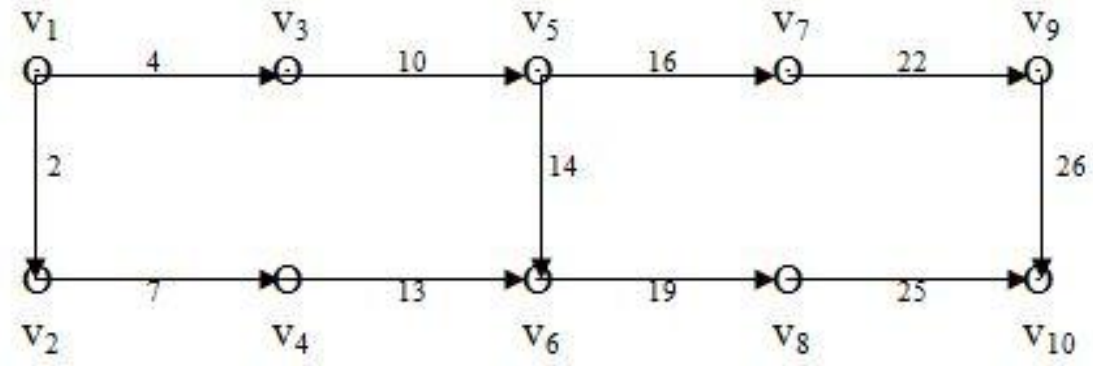

Fig 2.2a:-

Example (b) $G$ be the direct graph of two copies of cycle $C_{7}$ sharing a common edge.

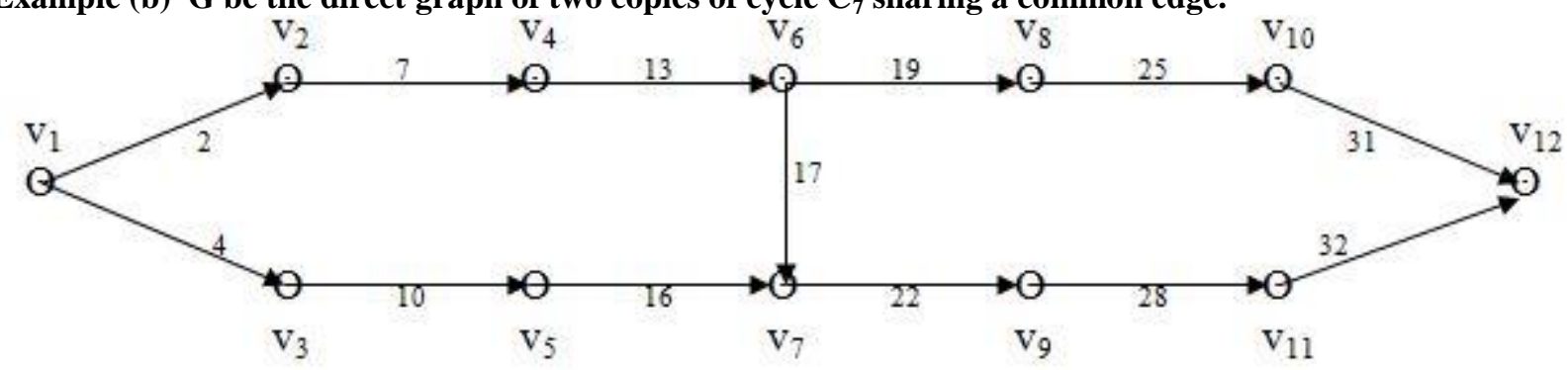

Fig 2.2b:-

\section{Theorem}

Direct graph of two copies of cycle $C_{n}(n>2)$ sharing a common vertex admits linear prime labeling.

\section{Proof:}

Let $\mathrm{G}$ be the graph and let $\mathrm{v}_{1}, \mathrm{v}_{2},---, \mathrm{v}_{2 \mathrm{n}-1}$ are the vertices of $\mathrm{G}$.

Here $|\mathrm{V}(\mathrm{G})|=2 \mathrm{n}-1$ and $|\mathrm{E}(\mathrm{G})|=2 \mathrm{n}$.

Define a function $\mathrm{f}: \mathrm{V} \rightarrow\{0,1,2,---, 2 \mathrm{n}-2\}$ by

Clearly $f$ is a bijection.

$$
f\left(v_{i}\right)=i-1, i=1,2,--, 2 n-1 \text {. }
$$

For the vertex labeling $\mathrm{f}$, the induced edge labeling $f_{l p l}^{*}$ is defined as follows 


$$
\begin{aligned}
& f_{l p l}^{*}\left(v_{1} v_{2}\right) \quad=2 \text {. } \\
& f_{l p l}^{*}\left(v_{2 i-1} v_{2 i+1}\right) \quad=6 \mathrm{i}-2 \text {, } \\
& f_{l p l}^{*}\left(v_{2 i} v_{2 i+2}\right) \quad=6 \mathrm{i}+1, \\
& f_{l p l}^{*}\left(v_{n-1} v_{n}\right) \quad=3 \mathrm{n}-4 . \\
& f_{l p l}^{*}\left(v_{n} v_{n+1}\right) \quad=3 \mathrm{n}-1 . \\
& f_{l p l}^{*}\left(v_{n+2 i-1} v_{n+2 i+1}\right) \quad=3 \mathrm{n}+6 \mathrm{i}-2, \quad \mathrm{i}=1,2,--, \frac{n-3}{2} \text {, if } \mathrm{n} \text { is odd. } \\
& f_{l p l}^{*}\left(v_{2 n-2} v_{2 n-1}\right) \quad=6 \mathrm{n}-7 . \\
& \mathrm{i}=1,2,---, \mathrm{n}-1, \text { if } \mathrm{n} \text { is odd. } \\
& \mathrm{i}=1,2,--, \frac{n-2}{2} \text {, if } \mathrm{n} \text { is even. } \\
& \mathrm{i}=1,2,---, \mathrm{n}-2 \text {, if } \mathrm{n} \text { is even } \\
& \mathrm{i}=1,2,--, \frac{n-3}{2} \text {, if } \mathrm{n} \text { is odd. } \\
& \text { Clearly } f_{l p l}^{*} \text { is an injection. } \\
& \text { gcin of }\left(\mathrm{v}_{\mathrm{n}}\right) \\
& =\operatorname{gcd} \text { of }\left\{f_{l p l}^{*}\left(v_{n-2} v_{n}\right), f_{l p l}^{*}\left(v_{n-1} v_{n}\right)\right\} \\
& =\operatorname{gcd} \text { of }\{3 n-5,3 n-4\}=1 \text {. } \\
& \operatorname{gcin} \text { of }\left(\mathrm{v}_{2 \mathrm{n}-1}\right) \\
& =\operatorname{gcd} \text { of }\left\{f_{l p l}^{*}\left(v_{2 n-3} v_{2 n-1}\right), f_{l p l}^{*}\left(v_{2 n-2} v_{2 n-1}\right)\right\} \\
& =\operatorname{gcd} \text { of }\{6 n-8,6 n-7\}=1 \text {. }
\end{aligned}
$$

So, gcin of each vertex of in degree greater than one is 1 .

Hence $G$, admits linear prime labeling.

Example (a) $G$ be the direct graph of two copies of cycle $C_{6}$ sharing a common vertex

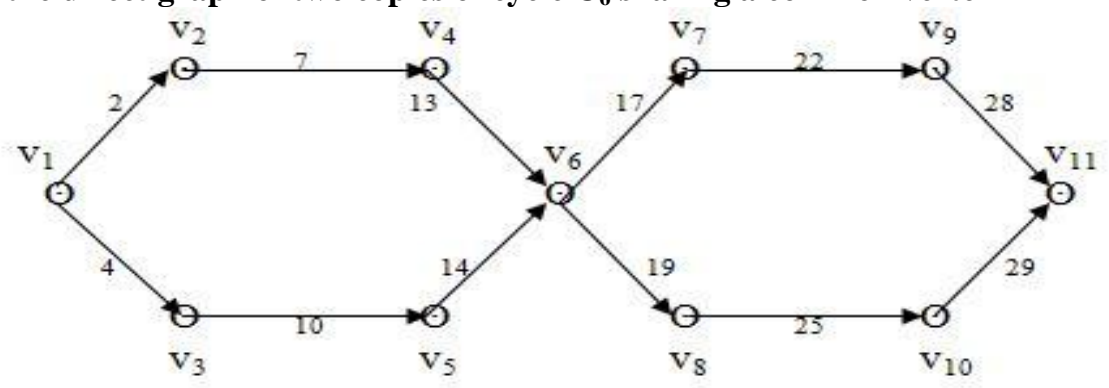

Fig 2.3a:-

Example (b) $G$ be the direct graph of two copies of cycle $C_{5}$ sharing a common vertex.

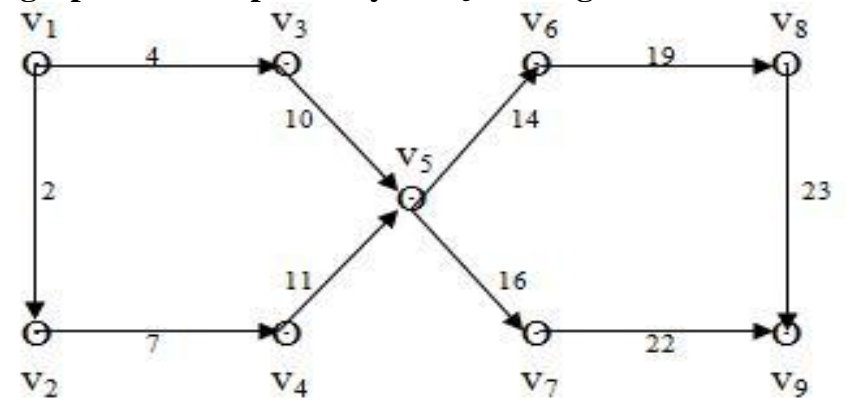

Fig 2.3b:-

\section{Theorem}

Let $G$ be the graph obtained by joining two copies of cycle $C_{n}(n>2)$ by an edge. Direct graph of $G$ admits linear prime labeling.

\section{Proof:}

Let $\mathrm{G}$ be the graph and let $\mathrm{v}_{1}, \mathrm{v}_{2},---, \mathrm{v}_{2 \mathrm{n}}$ are the vertices of $\mathrm{G}$.

Here $|\mathrm{V}(\mathrm{G})|=2 \mathrm{n}$ and $|\mathrm{E}(\mathrm{G})|=2 \mathrm{n}+1$.

Define a function $\mathrm{f}: \mathrm{V} \rightarrow\{0,1,2,---, 2 \mathrm{n}-1\}$ by

$$
f\left(v_{i}\right)=i-1, i=1,2,---2 n .
$$

Clearly $\mathrm{f}$ is a bijection. 
For the vertex labeling $\mathrm{f}$, the induced edge labeling $f_{l p l}^{*}$ is defined as follows
$f_{l p l}^{*}\left(v_{1} v_{2}\right)$
$=2$.
$f_{l p l}^{*}\left(v_{2 i-1} v_{2 i+1}\right)$
$=6 \mathrm{i}-2$,
$f_{l p l}^{*}\left(v_{2 i} v_{2 i+2}\right)$
$=6 \mathrm{i}+1$,
$f_{l p l}^{*}\left(v_{n-1} v_{n}\right)$
$=3 \mathrm{n}-4$.
$f_{l p l}^{*}\left(v_{n} v_{n+1}\right)$
$=3 \mathrm{n}-1$.
$f_{l p l}^{*}\left(v_{n+1} v_{n+2}\right)$
$=3 n+2$.
$f_{l p l}^{*}\left(v_{n+2 i-1} v_{n+2 i+1}\right)$
$=3 n+6 i-2$,
$\mathrm{i}=1,2,---, \frac{n-1}{2}$,if $\mathrm{n}$ is odd.
$\mathrm{i}=1,2,---\frac{n-2}{2}$, if $\mathrm{n}$ is even.
$f_{l p l}^{*}\left(v_{n+2 i} v_{n+2 i+2}\right)$
$=3 n+6 i+1$,
$f_{l p l}^{*}\left(v_{2 n-1} v_{2 n}\right)$
$=6 n-4$.
$\mathrm{i}=1,2,---\frac{n-1}{2}$,if $\mathrm{n}$ is odd.
$\mathrm{i}=1,2,---, \frac{n-2}{2}$, if $\mathrm{n}$ is even.
$\mathrm{i}=1,2,---\frac{n-3}{2}$, if $\mathrm{n}$ is odd
$\mathrm{i}=1,2,---\frac{n-2}{2}$, if $\mathrm{n}$ is even.
Clearly $f_{l p l}^{*}$ is an injection.
gcin of $\left(\mathrm{v}_{\mathrm{n}}\right)$
$=\operatorname{gcd}$ of $\left\{f_{l p l}^{*}\left(v_{n-2} v_{n}\right), f_{l p l}^{*}\left(v_{n-1} v_{n}\right)\right\}$
$=\operatorname{gcd}$ of $\{3 n-5,3 n-4\}$
$=1$.
$\operatorname{gcin}$ of $\left(\mathrm{v}_{2 \mathrm{n}}\right)$
$=\operatorname{gcd}$ of $\left\{f_{l p l}^{*}\left(v_{2 n-2} v_{2 n}\right), f_{l p l}^{*}\left(v_{2 n-1} v_{2 n}\right)\right\}$
$=\operatorname{gcd}$ of $\{6 n-5,6 n-4\}$
$=1$.

So, $\boldsymbol{g c i n}$ of each vertex of in degree greater than one is 1 .

Hence $\mathrm{G}$, admits linear prime labeling.

Example (a) $G$ be the direct graph of two copies of cycle $C_{7}$ joined by an edge.

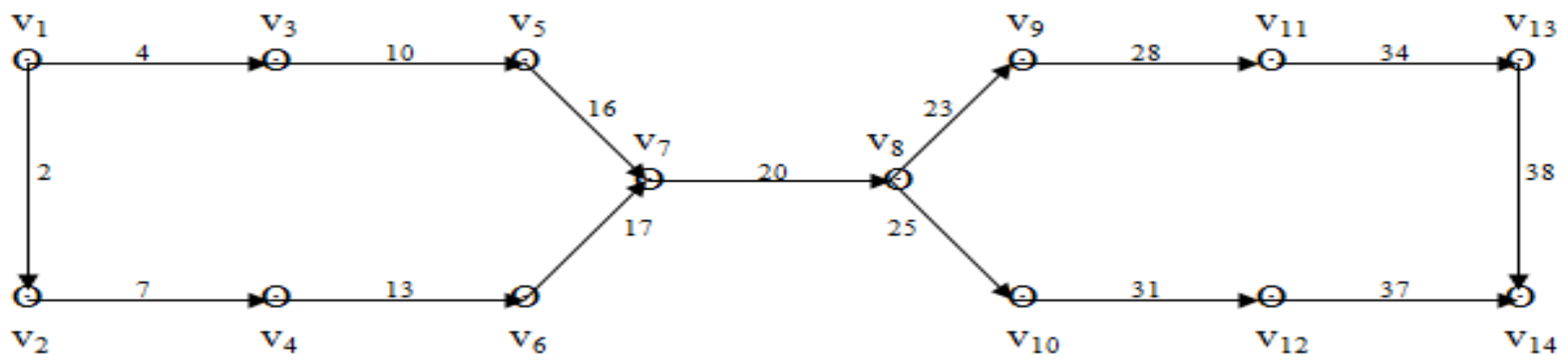

Fig 2.4a:-

Example (b) $G$ be the direct graph of two copies of cycle $C_{6}$ joined by an edge.

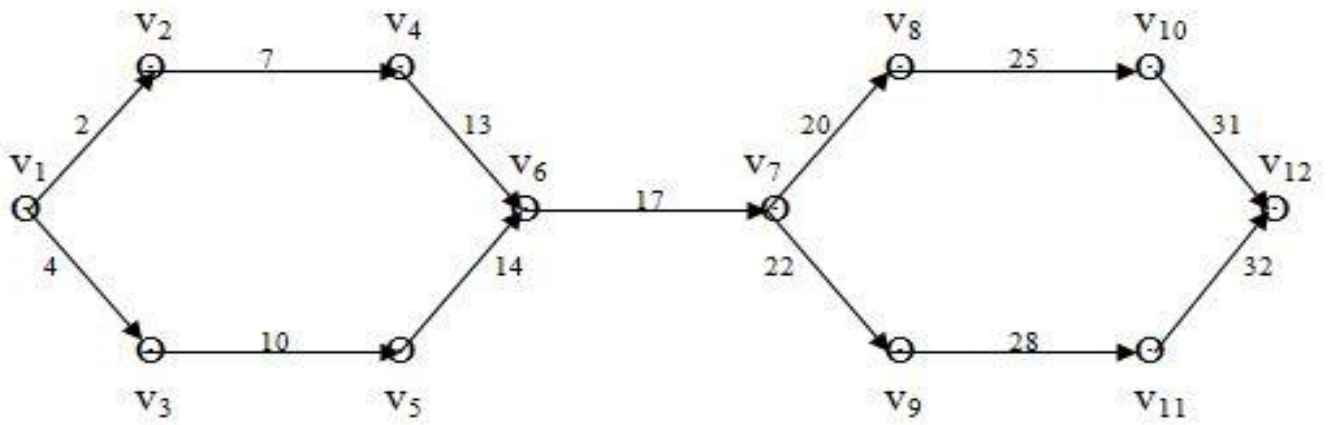

Fig 2.4b:- 


\section{Theorem}

Let $G$ be the graph obtained by joining one end vertex of a path $P_{m}$ to any vertex of a cycle $C_{n}(n>2)$. Direct graph of $\mathrm{G}$ admits linear prime labeling.

\section{Proof:}

Let $\mathrm{G}$ be the graph and let $\mathrm{v}_{1}, \mathrm{v}_{2},---, \mathrm{v}_{\mathrm{n}+\mathrm{m}-1}$ are the vertices of $\mathrm{G}$.

Here $|\mathrm{V}(\mathrm{G})|=\mathrm{n}+\mathrm{m}-1$ and $|\mathrm{E}(\mathrm{G})|=\mathrm{n}+\mathrm{m}-1$.

Define a function $\mathrm{f}: \mathrm{V} \rightarrow\{0,1,2,---, \mathrm{n}+\mathrm{m}-2\}$ by

Clearly $\mathrm{f}$ is a bijection.

$$
f\left(v_{i}\right)=i-1, i=1,2,---, n+m-1 \text {. }
$$

For the vertex labeling $\mathrm{f}$, the induced edge labeling $f_{l p l}^{*}$ is defined as follows

$$
\begin{aligned}
& f_{l p l}^{*}\left(v_{1} v_{2}\right) \quad=2 \text {. } \\
& f_{l p l}^{*}\left(v_{2 i-1} v_{2 i+1}\right) \quad=6 \mathrm{i}-2 \\
& f_{l p l}^{*}\left(v_{2 i} v_{2 i+2}\right)=6 \mathrm{i}+1, \\
& f_{l p l}^{*}\left(v_{n-1} v_{n}\right) \quad=3 \mathrm{n}-4 . \\
& f_{l p l}^{*}\left(v_{n+i-1} v_{n+i}\right) \quad=3 \mathrm{n}+3 \mathrm{i}-4 \text {, } \\
& \text { Clearly } f_{l p l}^{*} \text { is an injection. } \\
& \text { gcin of }\left(\mathrm{v}_{\mathrm{n}}\right) \\
& =\operatorname{gcd} \text { of }\left\{f_{l p l}^{*}\left(v_{n-2} v_{n}\right), f_{l p l}^{*}\left(v_{n-1} v_{n}\right)\right\} \\
& =\operatorname{gcd} \text { of }\{3 n-5,3 n-4\} \\
& =1 \text {. }
\end{aligned}
$$

So, gcin of each vertex of in degree greater than one is 1 .

Hence $G$, admits linear prime labeling.

Example (a) $G$ be the direct graph of a path $P_{4}$ joined to a cycle $C_{6}$.

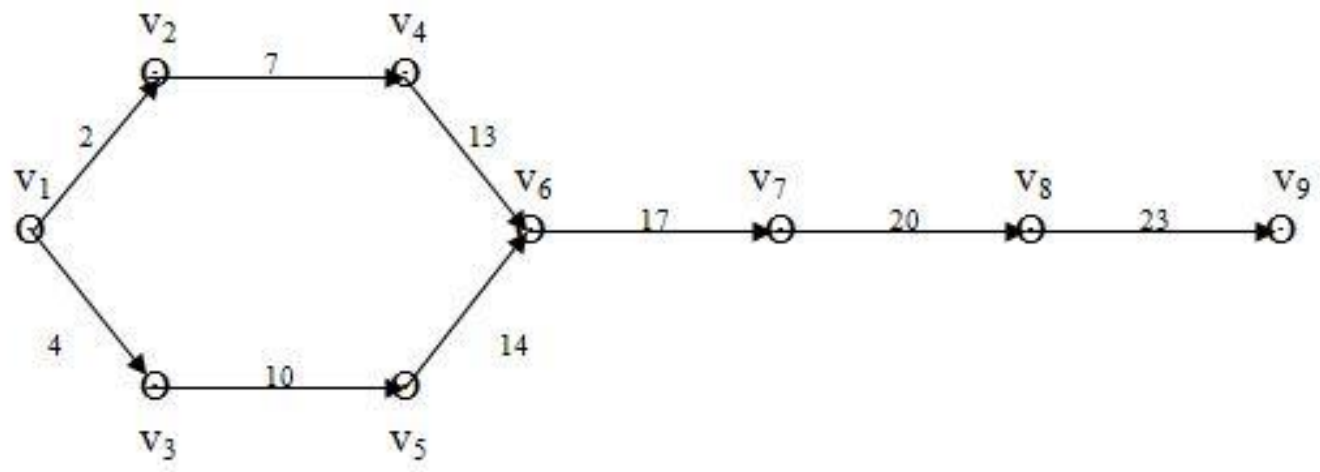

Fig 2.5a:-

Example (b) $G$ be the direct graph of a path $P_{4}$ joined to a cycle $C_{5}$.

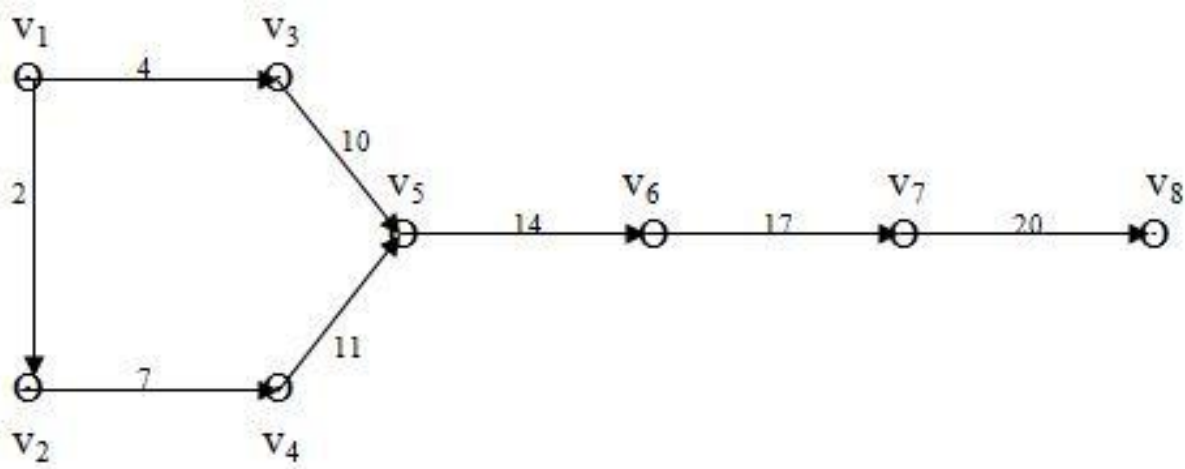

Fig 2.5b:- 


\section{Theorem}

Let $\mathrm{G}$ be the graph obtained by joining two copies of a path $\mathrm{P}_{m}$ to two consecutive vertices of a cycle $C_{n}(n>2)$.

Direct graph of $\mathrm{G}$ admits linear prime labeling.

\section{Proof:}

Let $\mathrm{G}$ be the graph and let $\mathrm{v}_{1}, \mathrm{v}_{2},---, \mathrm{v}_{\mathrm{n}+2 \mathrm{~m}-2}$ are the vertices of $\mathrm{G}$.

Here $|V(G)|=n+2 m-2$ and $|E(G)|=n+2 m-2$.

Define a function $\mathrm{f}: \mathrm{V} \rightarrow\{0,1,2,---, \mathrm{n}+2 \mathrm{~m}-3\}$ by

Clearly $\mathrm{f}$ is a bijection.

$$
f\left(v_{i}\right)=i-1, i=1,2,---n+2 m-2 \text {. }
$$

For the vertex labeling $\mathrm{f}$, the induced edge labeling $f_{l p l}^{*}$ is defined as follows

$$
\begin{array}{llr}
f_{l p l}^{*}\left(v_{1} v_{2}\right) & =2 . & \\
f_{l p l}^{*}\left(v_{2 i-1} v_{2 i+1}\right) & =6 \mathrm{i}-2, & \mathrm{i}= \\
& =6 \mathrm{i}+1, & \mathrm{i}= \\
f_{l p l}^{*}\left(v_{2 i} v_{2 i+2}\right) & \mathrm{i}= \\
f_{l p l}^{*}\left(v_{n-1} v_{n}\right) & =3 \mathrm{n}-4 . \\
\text { Clearly } f_{l p l}^{*} \text { is an injection. } & & \\
\operatorname{gcin} \text { of }\left(\mathrm{v}_{\mathrm{n}}\right) & & \operatorname{gcd} \text { of }\left\{f_{l p l}^{*}\left(v_{n-2} v_{n}\right), f_{l p l}^{*}\left(v_{n-1} v_{n}\right)\right\} \\
& & =\operatorname{gcd} \text { of }\{3 \mathrm{n}-5,3 \mathrm{n}-4\}
\end{array}
$$

$$
\begin{aligned}
& \mathrm{i}=1,2,---, \frac{n-1}{2}+\mathrm{m}-1 \text { if } \mathrm{n} \text { is odd. } \\
& \mathrm{i}=1,2,---, \frac{n-2}{2}+\mathrm{m}-1 \text { if } \mathrm{n} \text { is even. } \\
& \mathrm{i}=1,2,---, \frac{n-3}{2}+\mathrm{m}-1 \text { if } \mathrm{n} \text { is odd. } \\
& \mathrm{i}=1,2,---, \frac{n-2}{2}+\mathrm{m}-1 \text { if } \mathrm{n} \text { is even. }
\end{aligned}
$$

Hence $\mathrm{G}$, admits linear prime labeling.

Example (a) $G$ be the direct graph of two copies of path $P_{4}$ joined to two consecutive vertices of cycle $C_{6}$.

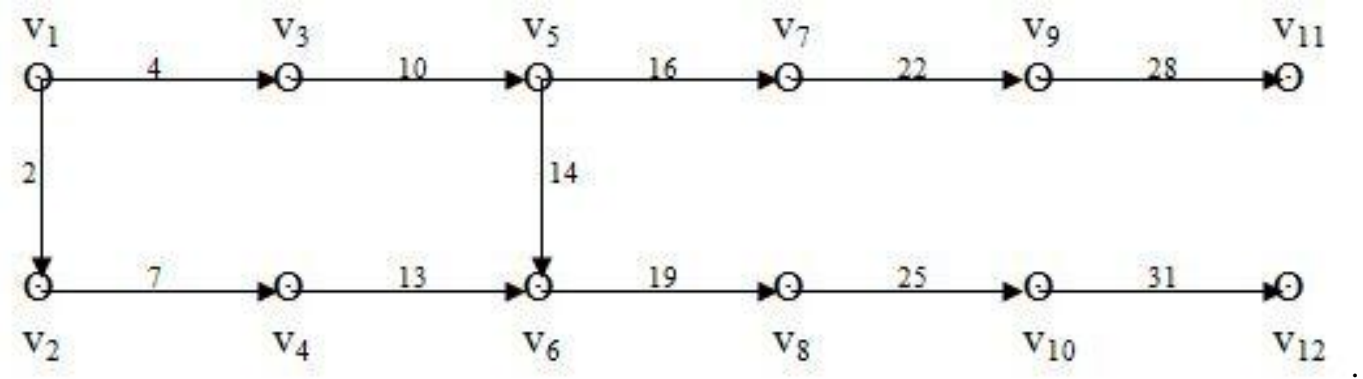

Fig 2.6a:-

Example (b) $G$ be the direct graph of two copies of path $P_{4}$ joined to two consecutive vertices of cycle $C_{5}$.

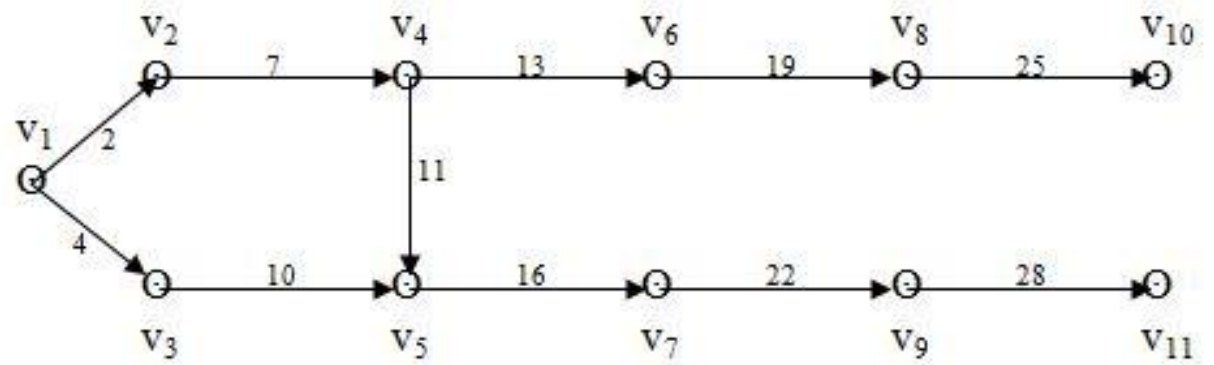

Fig 2.6b:- 


\section{References:-}

1. Apostol. Tom M, Introduction to Analytic Number Theory, Narosa, (1998).

2. F Harary, Graph Theory, Addison-Wesley,Reading, Mass, (1972).

3. Joseph A Gallian, A Dynamic Survey of Graph Labeling, The Electronic Journal of Combinatorics(2015), \#DS6,Pages 1 - 389.

4. T K Mathew Varkey, Some Graph Theoretic Operations Associated with Graph Labelings, PhD Thesis,University of Kerala 2000. 